\title{
The application of Mike Urban model in drainage and waterlogging in Lincheng county, China
}

\author{
Qinghua Luan ${ }^{1,2}$, Kun Zhang ${ }^{1,3}$, Jiahong Liu ${ }^{1,3}$, Dong Wang ${ }^{1,3}$, and Jun Ma ${ }^{1,2}$ \\ ${ }^{1}$ School of Water Conservancy and Hydroelectric Power, Hebei University of Engineering, \\ Handan 056021, Hebei, China \\ ${ }^{2}$ Hebei Provincial Research Center of Water Ecological Civilization \& Social Governance, \\ Handan 056038, Hebei, China \\ ${ }^{3}$ Institute of Water Resource, China Institute of Water Resources and Hydropower Research, \\ Beijing 100038, China \\ Correspondence: Qinghua Luan (carol97011202@163.com)
}

Received: 31 December 2017 - Accepted: 10 February 2018 - Published: 5 June 2018

\begin{abstract}
Recently, the water disaster in cities especially in Chinese mountainous cities is more serious, due to the coupling influences of waterlogging and regional floods. It is necessary to study the surface runoff process of mountainous cities and examine the regional drainage pipeline network. In this study, the runoff processes of Lincheng county (located in Hebei province, China) in different scenarios were simulated through Mike Urban model. The results show that all of the runoff process of the old town and the new residential area with larger slope, is significant and full flow of these above zones exists in the part of the drainage pipeline network; and the overflow exists in part of the drainage pipeline network when the return period is ten years or twenty years, which illuminates that the waterlogging risk in this zone of Lincheng is higher. Therefore, remodeling drainage pipeline network in the old town of Lincheng and adding water storage ponds in the new residential areas were suggested. This research provides both technical support and decision-making reference to local storm flood management, also give the experiences for the study on the runoff process of similar cities.
\end{abstract}

\section{Introduction}

In the developing countries, the rapid development of economy, industrialization and urbanization have changed the state of climate and underlying surface, and resulted in frequent extreme events such as rainstorms and droughts $(\mathrm{Tu}$, 2014), which is especially significant in China. Furthermore, in China, most of urban drainage pipeline network in the counties have not been constructed, the designed standard of pipeline is low, the standards of municipal are unreasonable and are not uniform with that of water authority (Xie et al., 2016; EWRI of ASCE, 2017), which also resulted in the increase of urban flood disasters, especially in typical mountainous cities. Therefore, it is crucial to study the mechanism of runoff generation and forecast the evolution road of urban waterlogging, especially in the typical developing mountain cities.
Several studies on urban waterlogging have been carried out in China and abroad, and many digital hydrological models have been applied to simulate the process of urban surface runoff and the running situation of drainage pipeline network (Zhou, 2014). Because Mike Urban model has complete urban drainage pipeline system, a friendly version, a good linking with GIS and has been widely used for types of fields, this model was chosen by many researchers. Hlodversdottir et al. (2015) built the surface runoff and drainage network model of the coastal area based on Mike Urban, and evaluated the risk of waterlogging and the net load of drainage pipeline in the central of the Reykjavík. Bouchenafa et al. (2014) built regional Mike Urban model of the urban underground transportation network, simulated the water dynamic processes of urban subway network and improved the scheme of urban flood control. 


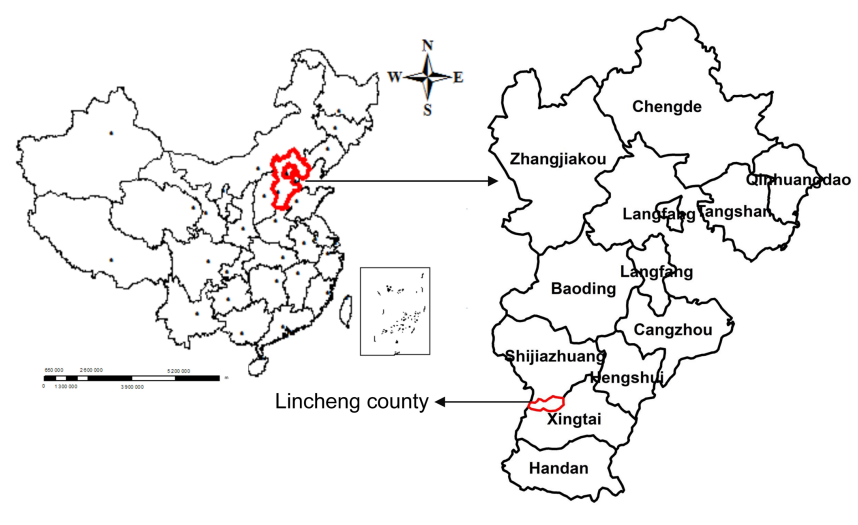

Figure 1. Study area location.

However, the researches on Mike Urban model in the mountain city of semi-arid area is relatively few. So the process study of surface runoff and drainage network in mountainous area is necessary. In this study, the drainage waterlogging situation in Lincheng County in different scenarios would be illustrated through Mike Urban model, which not only can illuminate the regional situation of drainage pipeline networks under different rainwater, but also can provide technology for the urban floods forecast and future waterlogging control. Moreover, the related results also provide decision-making reference for the planning and construction of drainage pipelines network in typical semi-arid mountainous cities.

\section{Study area and data collection}

\subsection{Study area}

Lincheng County as a mountainous county is located in Hebei Province, China and in the eastern foot of Taihang Mountain (Fig. 1). There are there geomorphic types: mountainous in the west, hilly in the middle and plain in the east, with the proportions of 35,50 and $15 \%$ respectively. This study area is the downtown of Lincheng County, covering an area of about $14 \mathrm{~km}^{2}$, has no hydraulic connection with the surrounding rivers. The south-north water diversion canal through the eastern region and also has no hydraulic connection with the drainage networks. The study area consists of three major parts (NORENDAR International Ltd., 2016): the western part is the old town, the drainage infrastructures are old and the pipeline network is complicated; the central part is a new residential area nearby the mountain; the eastern part as the new urban area is the education land and industrial park under development, the green area of this part is large and fields and ravines are on both sides of the road.
Table 1. The characteristics of designed rainfall processes.

\begin{tabular}{lrrrr}
\hline $\begin{array}{l}\text { Return } \\
\text { period }\end{array}$ & $\begin{array}{r}\text { Three } \\
\text { years }\end{array}$ & $\begin{array}{r}\text { Five } \\
\text { years }\end{array}$ & $\begin{array}{r}\text { Ten } \\
\text { years }\end{array}$ & $\begin{array}{r}\text { Twenty } \\
\text { years }\end{array}$ \\
\hline $\begin{array}{l}\text { Rainfall peak } \\
\left(\mathrm{mm} \mathrm{min}^{-1}\right)\end{array}$ & 2.42 & 2.70 & 4.00 & 4.56 \\
\hline $\begin{array}{l}\text { Total } \\
(\mathrm{mm})\end{array}$ & 99.60 & 122.60 & 158.20 & 195.60 \\
\hline
\end{tabular}

\subsection{Drainage pipeline network}

The drainage pipeline networks combining of western part and central part is an independent system and that of eastern part is also independent. The lengths of the drainage pipes and the elevations of the drainage wells can be got through the regional construction planning. Then, through ArcGIS, the drainage pipeline network was successfully digitized and the corresponding properties of the confluence nodes were got. In order to reduce the simulation error, the topologic relation of the pipeline network was checked. The detailed information and data of pipeline nodes and drainage pipeline network were got through the information database of Mike Urban model (Yao, 2012). Eventually, there are 120 confluence nodes and three drainage outlets in the study area. According to the statistic results, there are 121 concrete round pipes in total, of which the total length is about $47738.6 \mathrm{~m}$, and the main diameter of the pipe is $0.6,0.8$ and $1.2 \mathrm{~m}$. The elevation range of inner base of the pipeline network node is between 77 to $133.8 \mathrm{~m}$ (Fig. 2).

\subsection{Rainfall data}

\subsubsection{Observed rainfall data}

The observed rainfall processes were based on the gauge monitoring in study area and supplied by Hebei Hydrology and Water Resources Investigation Bureau. Two typical precipitation processes (Fig. 3) were selected for model calibration and validation, which is "7.19" (19 July 2016) and “7.06” (6 July 2017) respectively.

\subsubsection{Designed rainfall data}

Due to the lack of detailed observed rainfall data, the designed rainfall processes in $24 \mathrm{~h}$ of three years, five years, ten years and twenty years were calculated according to the local storm intensity formula in this research (Viglione and Blöschl, 2009; Han, 2015). In order to shorten the rainfall interval, the last processes of different return periods were computed through the coupling of $24 \mathrm{~h}$ processes and Chicago rainstorm formula (Cen, 1998). The rainfall peak and total volume of the different scenarios are shown in Table 1 . 


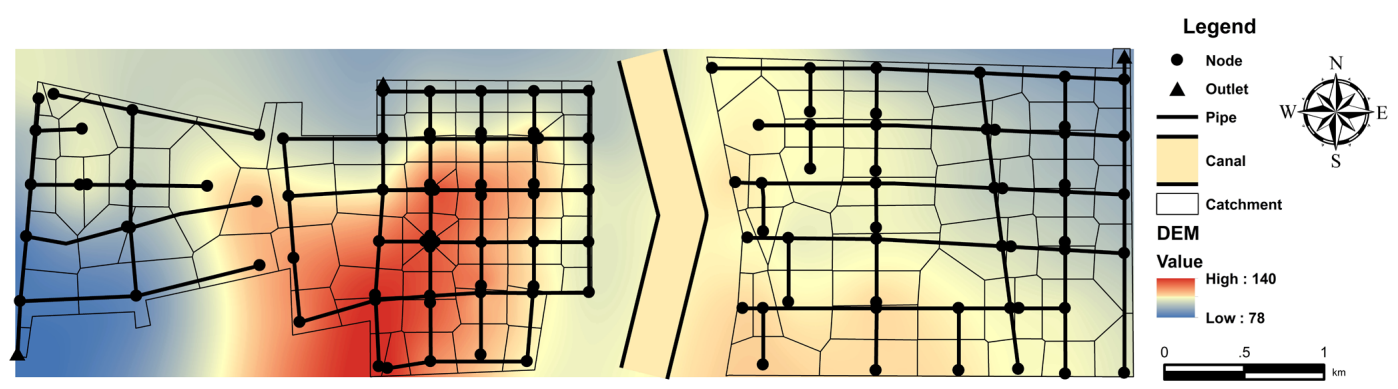

Figure 2. The drainage pipeline networks of the study area.

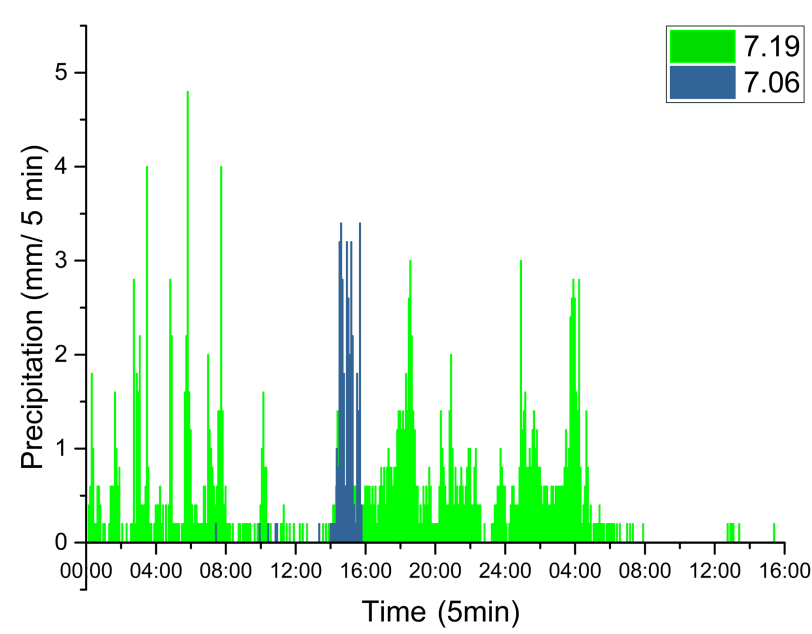

Figure 3. "7.19" and "7.06" typical precipitation processes.

\section{Model construction}

\subsection{Sub-catchments division}

The sub-catchment division is based on the digitized results of drainage pipeline network. In Mike urban model system, the confluence node is set as the central of the sub-catchment, and the sub-catchments of study area can be automatically divided according to Theisen polygons (USEPA, 1999; Ahmadi, 2012). Because the elevation of underlying surface in the study area has significant distribution change in the space, the automatic division results were checked and manually adjusted according to the actual confluence situation, in order to improve the simulation accuracy. At last, the study area was divided into 122 sub-catchments (Fig. 2).

\subsection{Initial value of model parameter}

The parameters of the sub-catchment area were set after the division was completed. Firstly, the underlying surface layers with different land use types were loaded into the model; there are four types of land use in Lincheng: green area, building area, transportation area and integrated land use, of which the corresponding impervious percentages are re-
Table 2. The empirical parameters of Mike21.

\begin{tabular}{lrrrr}
\hline Parameter & $\begin{array}{r}\text { Time } \\
\text { step (s) }\end{array}$ & $\begin{array}{r}\text { Drying } \\
\text { depth (m) }\end{array}$ & $\begin{array}{r}\text { Flooding } \\
\text { depth }(\mathrm{m})\end{array}$ & $\begin{array}{r}\text { Manning } \\
\text { number }\end{array}$ \\
\hline Value & 1 & 0.002 & 0.003 & 0.03 \\
\hline
\end{tabular}

spectively 20, 90, 80 and $50 \%$ according to the local planning (Kim et al., 2005). Secondly, the corresponding impervious percentages of each layer were set and input to the model. Lastly, the initial impervious percentages of each subcatchment were automatically calculated through the model. The other model parameters were set according to the recommendation value of the model handbook and the empirical range of actual situation (Son et al., 2016) (Table 4).

\subsection{Model calibration and verification}

In this paper, the Mike flood model coupled Mike21 and Mike Urban was used to simulate the surface overflowing process and the waterlogging situation of drainage pipeline networks (DHI, 2012). The properties of buildings and roads and DEM were pretreated through ArcGIS and the basic Mike21 files were completed through Mike Zero after the basic files superposition. Through Mike model, the elevation of the buildings and roads were revised and the land values were set in order to ensure the study area is close. The parameters of Mike21 is empirical (Table 2) due to their insensitivity. Mike21 was coupled with Mike Urban through Mike flood platform. Then, the urban pipe drainage networks were linked with two-dimensional surface flow, which is applied for the overflow simulation. The "7.19" and "7.06" rainfall processes were chosen for model calibration and validation, respectively. The parameters were calibrated and validated through comparing with the measured water depth (MWD) and the simulated water depth (SWD) of typical runoff processes. The relative error (RE) between the MWD and the SWD was adopted as the statistical index and the simulated results are shown that all of the REs conform with the related regulation (Rong et al., 2017) (Table 3). The calibrated parameters are listed in Table 4. 

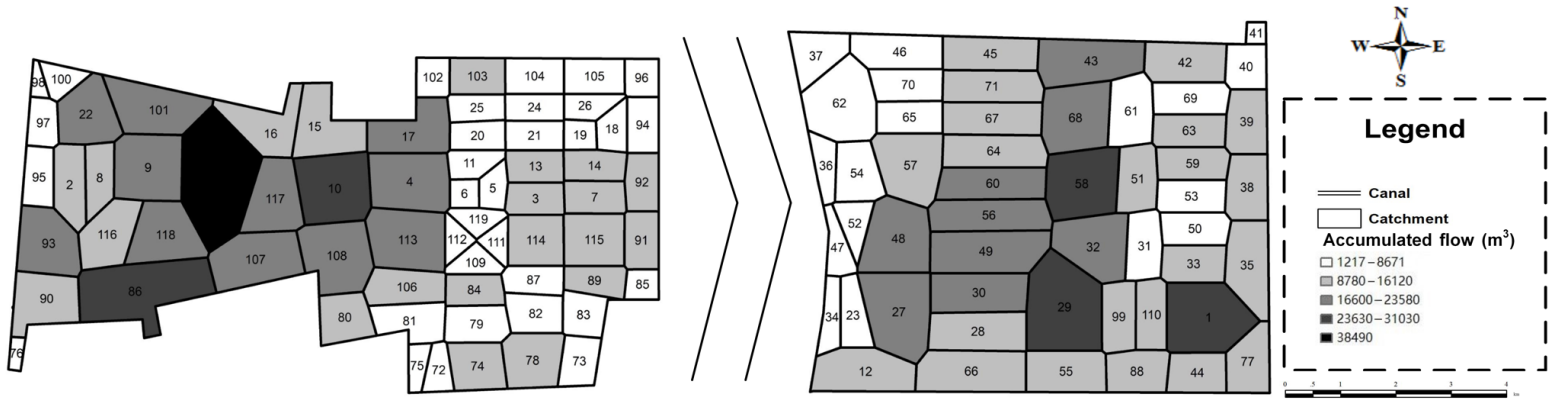

Figure 4. The regional distribution of surface accumulated flow in different sub-catchments.

Table 3. Simulated results of calibration and validation.

\begin{tabular}{l|rrr|rrr}
\hline Typical process & \multicolumn{2}{|c|}{7.19} & \multicolumn{3}{c}{7.06} \\
\hline Node No & MWD (cm) & SWD (cm) & RE (\%) & MWD (cm) & SWD (cm) & RE (\%) \\
\hline 5 & 10 & 9.3 & -7 & 10 & 9.5 & -5 \\
62 & 13 & 13.4 & 3.1 & 7 & 7.5 & 7.1 \\
92 & 8 & 8.9 & 11.3 & 6 & 6.4 & 6.7 \\
107 & 15 & 15.6 & 4 & 10 & 10.8 & 8 \\
\hline
\end{tabular}

Table 4. Calibrated results of Mike urban parameters.

\begin{tabular}{lrr}
\hline Parameter & Initial value & Calibrated value \\
\hline $\begin{array}{l}\text { Average velocity of } \\
\text { surface confluence }\end{array}$ & 0.30 & 0.20 \\
Hydrological reduction & 0.9 & 0.9 \\
factor & & \\
Initial water loss & 0.0006 & 0.0015 \\
Manning coefficient of & 0.015 & 0.013 \\
pipeline & & \\
\hline
\end{tabular}

\section{Results and analysis}

The designed rainfall processes in different return periods were input and then the corresponding runoff processes were calculated through the calibrated model. In this study, the analysis of the different flood processes contains three aspects: typical waterlogging area, pipeline network load and typical overflow point (SAC, 2008). Detailed analysis in different aspects can indicates the surface runoff processes and the running state of the drainage pipeline network more clearly and be convenient for government to manage urban waterlogging and drainage network construction.

\subsection{Typical waterlogging area}

According to the simulated results, the peak runoff, accumulated flow and comprehensive runoff coefficient of subcatchment area increased slowly with the increase of rainfall. The peak of surface runoff in the study area in differ- ent return period appeared at 18:30. When the return period is twenty years, the comprehensive runoff coefficient is the largest, the value is 0.658 at 18:30. The waterlogged area includes 6 sub-catchments, and the surface runoff of the No. 99 sub-catchment in the old town area is the largest, and the peak runoff and accumulated flow of runoff during different return periods in this typical sub-catchment are shown in Table 5.

The regional situation of infrastructure construction combining the distribution of surface accumulated flow in twenty-year return periods (Fig. 4) illustrates that the waterlogging frequents of the old town and the joint zone between the old town and the new residential area are higher, because the corresponding elevation is low, thus the confluence speed is fast and the surface flow duration is short. In addition, the lack of drainage capacity in the old town and the improper joint between the new and old urban areas also cause severe waterlogging. Although the surface runoff in some eastern sub-catchments is large (Fig. 4), the related waterlogging situation is better, due to the large water permeability based on the large green area.

\subsection{Pipeline network load}

The simulated results show that in three-year return period, there are 17 pressured pipelines in the drainage networks, of which 3 and 14 pipelines are under full pressure and partial pressure respectively; while in twenty-year return period, 4 and 20 pipelines are under full pressure and partial pressure, respectively. With the increase of the return period, the number of the pressured pipelines increases evidently, and the pressure and pressured duration also increase in the same 
Table 5. Runoff characteristics in different return periods in No. 99 sub-catchment.

\begin{tabular}{lrrrr}
\hline Return period & Three years & Five years & Ten years & Twenty years \\
\hline Peak runoff $\left(\mathrm{m}^{3} \mathrm{~s}^{-1}\right)$ & 3.92 & 4.36 & 5.20 & 5.94 \\
Maximum cumulative quantity $\left(\mathrm{m}^{3}\right)$ & 19520.9 & 24057.1 & 31106.9 & 384892 \\
Comprehensive runoff coefficient & 0.655 & 0.656 & 0.657 & 0.658 \\
\hline
\end{tabular}

Table 6. Total numbers of pressure pipeline in different return periods.

\begin{tabular}{lrrrr}
\hline $\begin{array}{l}\text { Pressure state } \\
\text { (bar) }\end{array}$ & $\begin{array}{r}\text { Three } \\
\text { years }\end{array}$ & $\begin{array}{r}\text { Five } \\
\text { years }\end{array}$ & $\begin{array}{r}\text { Ten } \\
\text { years }\end{array}$ & $\begin{array}{r}\text { Twenty } \\
\text { years }\end{array}$ \\
\hline Fully & 3 & 4 & 4 & 4 \\
Partial & 14 & 16 & 17 & 20 \\
\hline Total & 17 & 20 & 21 & 24 \\
\hline
\end{tabular}

Table 7. Total overflow nodes numbers of each district in different return periods.

\begin{tabular}{lrrrr}
\hline $\begin{array}{l}\text { Return } \\
\text { period }\end{array}$ & $\begin{array}{r}\text { Three } \\
\text { years }\end{array}$ & $\begin{array}{r}\text { Five } \\
\text { years }\end{array}$ & $\begin{array}{r}\text { Ten } \\
\text { years }\end{array}$ & $\begin{array}{r}\text { Twenty } \\
\text { years }\end{array}$ \\
\hline Old town & 5 & 5 & 5 & 6 \\
New district & 4 & 4 & 5 & 6 \\
Industrial zone & 3 & 3 & 4 & 5 \\
\hline
\end{tabular}

pressured pipeline. In No. 98 and No. 107 sub-catchment of the old town, their pipelines are pressured at first and under pressure until the runoff ends. The pressured pipelines in the old town account for the main of the total ones, which is consistent with the simulated waterlogging situation and the related analysis. The pipelines nearby the outlet are also easily pressured, due to the runoff confluence. With the duration of rainfall, the pipelines in the other areas are gradually pressured. The number of pressured pipelines in different return periods are shown in Table 6.

\subsection{Typical overflow point}

The simulated results also show that the overflow firstly occurred at the 96th node in any return period; the overflow appeared earlier (about 01:00), and existed until the rainfall ended in twenty-year return period. Both the water level and the discharge of overflow in the 102th node are largest in any return period. There are 12 overflow nodes in the study area, of which 5 nodes are located in the old town; and the overflow duration of the 96th node is about $20 \mathrm{~h}$, in three-year return period. While, there are 17 overflow nodes, of which 6 overflow nodes are located in the old town, and the overflow duration of the 96th node is about $23 \mathrm{~h}$, in twenty- year return period. The overflow nodes numbers of each district in different return period are listed in Table 7.
With the increase of return period, the overflow nodes number of drainage pipeline network increases, the overflow appears earlier and the overflow duration increases. Additionally, the overflow nodes with high water level are mainly located in the western old town due to the poor drainage capacity and low elevation; while some overflow nodes with low water level are located in the central and eastern urban areas. These results and analysis are both consistent with the simulated results and the corresponding analysis of waterlogging and pipeline network load.

\section{Conclusions}

In this research, the Mike urban in Lincheng city was successfully constructed. The waterlogging situation of different surface runoff processes and running state of drainage pipeline network in the study area were illuminated. The simulated results show that the water logging pressure in typical mountain part and the old town is greater than that of the plain part and the new area. With the increase of the return period, the accumulated flow, the pressured pipeline number and the overflow nodes number accordingly increase.

The related analysis provides technical support for the early warning of urban waterlogging and construction of drainage infrastructures of study area, and gives references for the simulation of surface runoff process in mountainous cities.

Data availability. The data of this study came from the construction planning of lincheng County. We cooperated with the NORENDAR International Ltd. to complete the program. The content of urban planning and design is open and public in the followed URL: http://www.lincheng.gov.cn/index.aspx?lanmuid= $46 \&$ sublanmuid $=539 \& i d=642$. However, the urban drainage network data involved in this study is not publicly available. In addition, Lincheng County is a typical mountainous city with three different types of urban areas, and the urban drainage networks of each type are independent. Therefore, we chose Lincheng County as the research area.

Competing interests. The authors declare that they have no conflict of interest. 
Special issue statement. This article is part of the special issue "Innovative water resources management - understanding and balancing interactions between humankind and nature". It is a result of the 8th International Water Resources Management Conference of ICWRS, Beijing, China, 13-15 June 2018.

Acknowledgements. We are grateful to the NSF of Hebei, China (No. E2017402178), the NSFC (No. 51739011) and the NSF of Hebei Education, China (No. ZD2014020).

Edited by: Dingzhi Peng

Reviewed by: Meifang Ren and one anonymous referee

\section{References}

Ahmadi, Z.: Investigation of adequacy of Masal city drainage network and suggestions for improvement by using MIKE SWMM model, Iranian Water Res. J., 6, 93-103, 2012.

Bouchenafa, W., Mouhous-Voyneau, N., Sergent, P., and Brochet, J.: Study of flow in a staircase at subway station. Advances in Hydroinformatics, Springer, Singapore, 171-183, 2014.

Cen, G.: Research on rainfall pattern of urban design storm, Adv. in Water Sci., 1, 42-47, 1998.

DHI (Danish Hydraulic Institute): MIKE Urban User Manual, Denmark, 240 pp., 2012.

EWRI of ASCE: Standard guidelines for the drainage of urban stormwater systems, ASCE/EWRI45-05, Reston, Va: American Society of Civil Engineers, 60 pp., 2017.

Han, J. L.: Drainage waterlogging planning of small city based on Mike Urban, M.A. thesis, Zhejiang University of Technology, China, 2015.

Hlodversdottir, A. O., Bjornsson, B., Andradottir, H. O., Eliasson, J., and Crochet, P.: Assessment of flood hazard in a combined sewer system in Reykjavik city centre, Water Sci. Technol., 71, 1471-1477, https://doi.org/10.2166/wst.2015.119, 2015.
Kim, J. S., Ahn, J. H., Oh, T. S., and Moon, Y. I.: Runoff analysis of urban watershed using MIKE SWMM model, J. Korea Water Resour Assoc., 38, 907-916, https://doi.org/10.3741/JKWRA.2005.38.11.907, 2005.

NORENDAR International Ltd.: Control detailed control planning in Lincheng County, http://www.lincheng.gov.cn/index.aspx? lanmuid=46\&sublanmuid=539\&id=642 (last access: 21 February 2018), 2016.

Rong, M. A., Bai, T., Huang, Q., and Yang, W.: MIKE 21 model and its application on urban waterlogging simulation, J. Nat. Disast., 26, 172-179, https://doi.org/10.13577/j.jnd.2017.0420, 2017.

Son, A. L., Kim, B., and Han, K. Y.: A Simple and robust method for simultaneous consideration of overland and underground space in urban flood modeling, Water, 8, 494, https://doi.org/10.3390/w8110494, 2016.

Standardization administration of PRC (SAC): Standard for hydrological information and hydrological forecasting (GB/T 224822008), Standards Press of China, Beijing, China 11 pp., 2008.

Tu, C.: Application of computer simulation of urban stormwater: take Seongbuk of Dayu County as an example, M.A. thesis, Nanchang University, China, 2014.

USEPA (United States Environmental Protection Agency): Preliminary data summary of urban storm water best management practices, EPA, Washington, 214 pp., 1999.

Viglione, A. and Blöschl, G.: On the role of storm duration in the mapping of rainfall to flood return periods, Hydrol. Earth Syst. Sci., 13, 205-216, https://doi.org/10.5194/hess-13-2052009, 2009.

Xie, J. Q., Liao, Z. L., and Gu, X. Y.: Prediction and evaluation of waterlogging in highly urbanized areas based on Mike Urban: demonstrated on the example of Huoshan-Huimin drainage system in Shanghai, Energy Environ. Prot., 30, 44-49, https://doi.org/10.3969/j.issn.1006-8759.2016.05.010, 2016.

Yao, S. L.: Urban Drainage Systerm Modeling Research Based on Mike Flood, Ph.D. thesis, Beijing University of Technology, China, 2012.

Zhou, Q.: A Review of sustainable urban drainage systems considering the climate change and urbanization impacts, Water, 6, 976-992, https://doi.org/10.3390/w6040976, 2014. 